\title{
FACTORS AFFECTING RESEARCH PRODUCTIVITY OF PRODUCTION AND OPERATIONS MANAGEMENT GROUPS: AN EMPIRICAL STUDY
}

\author{
GEORGE C. HADJINICOLA AND ANDREAS C. SOTERIOU
}

Received 11 July 2004; Accepted 11 January 2005

This paper identifies factors that promote research productivity of production and operations management (POM) groups of researchers in US business schools. In this study, research productivity of a POM group is defined as the number of articles published per POM professor in a specific period of time. The paper also examines factors that affect research quality, as measured by the number of articles published per POM professor in journals, which have been recognized in the POM literature as an elite set. The results show that three factors increase both the research productivity and the quality of the articles published by professors of a POM group. These factors are (a) the presence of a POM research center, (b) funding received from external sources for research purposes, and (c) better library facilities. Doctoral students do assist in improving research quality and productivity, but they are not the driving force. These results have important implications for establishing policy guidelines for business schools. For example, real-world problems are funded by external sources and have a higher probability of publication. Furthermore, schools could place more emphasis on external funding, as most engineering schools do, since groups receiving external funding are more productive in terms of research.

Copyright (c) 2006 G. C. Hadjinicola and A. C. Soteriou. This is an open access article distributed under the Creative Commons Attribution License, which permits unrestricted use, distribution, and reproduction in any medium, provided the original work is properly cited.

\section{Introduction}

Research productivity in academic institutions is reflected in the number and quality of articles published by the affiliated faculty. Often, departments evaluate their faculty on their "publication count" (Jaunch and Glueck [18]). Research productivity evaluation has a significant impact on tenure decisions and promotions in general, salary raises, and mobility, especially in research-oriented schools. Given the importance of research productivity in academic institutions, a number of studies, in almost all major business disciplines, has addressed the issue. These studies can be classified into two broad categories. 
Studies in the first category evaluate research outlets in terms of their quality. The second category deals with studies that classify either individual researchers or departments in terms of their research productivity. Research productivity in these studies is usually defined as the number of articles published in a list of journals that usually emerges from the first category of studies mentioned above (e.g., Young et al. [37]; Malhotra and Kher [22]; Baden-Fuller et al. [2]).

Journal evaluation studies are either based on perceptual data provided by responding academics or objective data usually derived from citation indices. Such journal evaluation studies have been conducted in economics (Moore [24]; Skeels and Taylor [30]; Billings and Viksnins [6]; Hawkins et al. [16]; Liebowitz and Palmer [21]), accounting (Benjamin and Brenner [5]; Weber and Stevenson [35], finance (Coe and Weinstock [9, 10]), management (Sharplin and Marby [29]), and psychology (White and White [36]).

In production and operations management (POM), the first journal evaluation study was conducted by Saladin [28] who identified the journals that academics in the field of POM publish their research. Saladin also identified the journals that are more widely read by academics and managers of the field. Subsequently, Barman et al. [4] ranked twenty POM-related journals based on the perceptions provided by US-based members of the Decision Sciences Institute. Ansari et al. [1] determined a number of articles and their respective periodicals that could potentially be important to POM academics and managers. Studies by Vokurka [34] and Goh et al. [12] used objective citation indices measures to classify POM-related journals. Soteriou et al. [31] classified POM-related journals in terms of their quality and relevance based on the perceptions of European POM researchers. Barman et al. [3] report that the quality and relevance of POM journals, as perceived by US academics, remained constant when compared with the perceptual findings of the Barman et al. [4] study, and further comments on the differences between European and US academics, as identified by Soteriou et al. [31].

Studies assessing the research productivity of departments in academic institutions or individual researchers have been conducted in various disciplines such as in general business (Niemi [27]); Baden-Fuller et al. [2]), management (Stahl et al. [32]), marketing (Niemi [26]), finance (Klemkosky and Tuttle [19]; Ederington [11]; Niemi [25]), accounting (Jacobs et al. [17]), management information systems (Vogel and Wetherbe [33]; Grover et al. [14]), and economics (Graves et al. [13]; Laband [20]). The above studies usually rank departments according to the number of articles published in the journals of the field.

In the field of POM, Young et al. [37] classified POM researchers according to the number and quality of articles they published in the Barman et al. [4] list of POM-related journals, during the period 1989-1993. Malhotra and Kher [22] classified institutions in terms of the total number of articles and pages published in the top- 5 journals in the Barman et al. [4] list. These journals included Management Science, Decision Sciences, the Journal of Operations Management, IIE Transactions, and the International Journal of Production Research.

The above two lines of research focused their effort on the classification of either journals or institutions. A major issue that has not been examined in these studies is the identification of factors that either promote or impede academic research productivity. 
As such, the aim of this paper is to present an exploratory empirical study that identifies factors affecting the research productivity and the quality of articles of production and operations management groups (POMGs). We define a POMG to be the number of individuals housed in the same department and conducting research on POM topics. In this study, we have chosen POMGs to be the unit of analysis, since not all business schools have a distinct POM department. As such, it is not uncommon for POM researchers to belong to large departments that include other disciplines. We define the research productivity of a POMG to be the number of articles published per professor in a specific period of time. We also employ a measure of research quality which we define as the number of articles per professor that have appeared in a specific period of time in a set of prestigious journals of the POM field. This set of prestigious journals has been identified by Barman et al. [4].

The identification of factors promoting or impeding research productivity has been the focus of few studies in other disciplines. However, no such studies have been conducted in the POM discipline. For example, a study concerning research publications in finance (Borokhovich et al. [8]) showed that as faculty size increases, both the total number of publications and the per-faculty number of publications increase. Mitchell and Rebne [23] found that moderate amounts of consulting and teaching lead to an increase of academic research productivity. More specifically, they found that as much as four hours per week of consulting and as much as eight hours per week of teaching facilitate research productivity. Seniority has also been shown to be a factor leading to higher research productivity in a study by Bonzi [7]. Bonzi examined senior faculty at Syracuse University and showed that research productivity increases over time.

In a study related to the POM discipline, Hancock et al. [15] surveyed researchers who published in Management Science and Operations Research, during the period 19851989. In this study, researchers were classified into two groups, those with high publication rate (published more than thirteen articles) and those with lower publication rate (published less than seven articles). Hancock et al. [15] found that prolific researchers spend 32 percent less time on teaching-related activities and that the research productivity of such prolific researchers increases after receiving tenure. This result is compatible with Bonzi's [7] findings. Furthermore, respondents viewed administrative, committee, and teaching duties as the primary impediments to research productivity.

The results of our study indicate that the presence of a research center focusing on POM topics, as well as funding received from external sources for research purposes, increase both the POMG research productivity and quality of articles. The study also suggests that better library facilities further promote research productivity of researchers in terms of the number of articles and their quality. The number of doctoral students does assist in improving research quality and productivity, but cannot be considered as the driving force. These results have important implications for establishing policy guidelines for business schools.

The organization of the paper is as follows. Section 2 describes the research design adopted in the study. Section 3 includes the statistical analysis and discussion of the results. Finally, Section 4 summarizes the findings of this study, points out its limitations, and provides directions for future research. 


\section{Research design}

2.1. Survey instrument and description of the variables. Two types of information are required for the purposes of this study. First, information regarding factors that may drive the research productivity and the quality of articles published by POMGs. Second, information regarding the research output of a POMG. A survey instrument was designed for data collection, focusing on both objective and subjective information. Data were coded in a number of independent variables, which are presented in Table 2.1. As evident in Table 2.1, the variables characterize a number of dimensions that are traditionally thought to affect research productivity such as, funding, secretarial support, computer support, library facilities, the presence of a research center focusing on POM topics, the number of graduate students at the MBA, M.Sc., and Ph.D. levels, and the number of other disciplines housed under the same department.

Although present in the questionnaire, a number of independent variables were not considered in the study because respondents did not provide the necessary information. These variables include the average teaching load (hours taught per week), the average number of hours per week devoted to teaching undergraduate courses, and the number of hours per week devoted to teaching graduate courses. As a result, the impact of teaching load on productivity is not addressed in this study. This is certainly a limitation of the study. However, we believe that if our study had considered the impact of the average teaching load of a professor on his/her research productivity, the results would have been aligned with the conclusion of previous studies (Hancock et al. [15]; Mitchel and Rebne [23]). These studies have shown that, in general, research productivity of a professor is negatively affected by his/her teaching load. The following two dependent variables were used in this study.

Total-articles. Average number of articles per professor of the POMG, published during the period January 1990-December 1997.

Top-10-articles. Average number of articles per professor of the POMG, published during the period January 1990-December 1997 and classified by Barman et al. [4] as published in the top-10 journals in terms of quality.

The operationalization of the above two dependent variables was accomplished with the help of the ABI Inform database. In particular, study participants were asked to provide the names of professors conducting research on POM issues at their department or business school. These professors constitute the POMG of a department or a business school, as defined in our study. To maintain accuracy, these names were cross-checked with information provided by the university's web page. Using the names of these professors, we extracted all articles published by them in any journal listed in the ABI Inform database, for the eight-year period January 1990 until December 1997. In other words, we focused on the research output of POMGs in the nineties. Every time a professor's name appeared on an article, the POMG that he/she belonged to was credited one unit. Using the ABI Inform database, we also collected information regarding research publications in the top-10 journals identified in the study by Barman et al. [4]. The only journals in the Barman et al. [4] study that are not included in the ABI Inform database, and are excluded 
Table 2.1. The independent variables used in this study.

\begin{tabular}{|c|c|}
\hline Name & Description \\
\hline Center & Existence of a center conducting research on POM topics \\
\hline Num-MBAs & Number of MBA students admitted each year \\
\hline Undergraduate & Average number of students in undergraduate courses \\
\hline Graduate & Average number of students in graduate courses \\
\hline Doctoral & Number of doctoral students in the department \\
\hline POM-doctoral & $\begin{array}{l}\text { Number of doctoral students in the department } \\
\text { specializing in POM }\end{array}$ \\
\hline Num-graduate & $\begin{array}{l}\text { Number of graduate students pursuing an M.Sc. or M.A. } \\
\text { in the department (excluding MBAs) }\end{array}$ \\
\hline Num-graduate-POM & $\begin{array}{l}\text { Number of graduate students pursuing an M.Sc. or M.A. } \\
\text { in the department and specializing in POM }\end{array}$ \\
\hline Disciplines & $\begin{array}{l}\text { Number of other disciplines housed under the same department, } \\
\text { for example,business statistics, information systems, operations } \\
\text { research, and so forth }\end{array}$ \\
\hline Secret/profess & Secretaries per professor ratio \\
\hline Library-books & Perceived adequacy of the library concerning books in POM (1-7) \\
\hline Library-journals & Perceived adequacy of the library concerning journals in POM (1-7) \\
\hline Library-databases & Perceived adequacy of the library concerning databases in POM (1-7) \\
\hline Library & Perceived overall assessment of the library system (1-7) \\
\hline Computer-supp & Perceived overall assessment of the computer support services \\
\hline Computer-expend & $\begin{array}{l}\text { Amount of money spent, during the last three years, in the department } \\
\text { on computer support (hardware and software) }\end{array}$ \\
\hline Funds-internal & $\begin{array}{l}\text { Amount of money (research grants) allocated,during the last three years, } \\
\text { by the university to POM professors for research }\end{array}$ \\
\hline Funds-external & $\begin{array}{l}\text { Amount of money (research grants) allocated, during the last three years, } \\
\text { by external sources (NSF, private organizations, etc.) to POM professors } \\
\text { for research }\end{array}$ \\
\hline
\end{tabular}

from our study, are the International Journal of Production Research, Naval Research Logistics, and the Journal of the Operational Research Society. Since the size of the POMGs varies across universities, it was deemed important to normalize the dependent variables in order to ensure a fair comparison between large and small POMGs. The dependent variable total-articles was normalized by dividing the total number of articles published by professors of the POMG with the total number of professors in the group. Similarly, 
the dependent variable top-10-articles was normalized by dividing the total number of articles published by professors of the POMG in the top-10 journals with the total number of professors in the group.

2.2. Sampling. The sampling frame of our study comprised of all business schools in the US that are members of the widely recognized American Assembly of Collegiate School of Business (AACSB), which since 1997 has been renamed to AACSB-The International Association of Management Education. AACSB is a not-for-profit corporation of educational institutions, corporations, and other organizations, devoted to the promotion and improvement of higher education in business administration and management. Founded in 1916, AACSB is considered as the premier accrediting agency for bachelor's, master's, and doctoral degree programs in business administration and accounting.

A total of 328 business schools in the US were members of the AACSB when the study was initiated in December 1997. Contact information for POM professors was obtained from the school's web page on the Internet. The chairperson of each POM department was kindly requested to participate in the study. Whenever this was not possible due to the fact that some departments house more than one discipline, such as business statistics, information systems, or other, a single, preferably senior professor in POM was selected.

A cover letter was initially sent to all participants at each school through electronic mail, asking them to complete the questionnaire, which was made accessible on the Internet. If participating professors could not complete and submit the questionnaire in an electronic form, we provided the option to complete the questionnaire after sending it to them through fax or regular mail. In an effort to increase the response rate, three waves of reminders were sent to professors who did not respond during the period between December 1997 and March 1998. A total of 91 valid responses were received out of the 328 that were requested, representing a response rate of $27.74 \%$. Respondents represented universities from almost all geographical regions in the US.

\section{Analysis and discussion}

In this section, we provide a brief description of the data, followed by a set of propositions regarding factors affecting the research productivity and research quality of POMGs. The section also includes discussion on the findings.

3.1. Description of the data. Among the 91 respondents, 56 were full professors $(61.53 \%), 23$ were associate professors (25.27\%), and 12 were assistant professors (13.20\%). Among the 91 business schools that are represented in the study, 88 have an MBA program, 76 use the semester system, and 11 (12.08\%) have a center conducting research on POM issues. Nonresponse bias was assessed by examining differences along the variables, between our sample and our sampling frame. No significant differences were found. The average number of articles published per professor is about 3.5 in the 8-year period from January 1990 until December 1997. This is equivalent to 0.44 articles per year. In a study by Young et al. [37] it is reported that POM individuals that publish one 
article per year may be considered among the most active in the field (top-100 POM researchers). This is also evident in the study by Barman et al. [4]. The publication average in our study is about half the average of the top-100 POM researchers. This is expected since our study covers the entire population of POM researchers instead of focusing only on the most active.

Table 3.1 provides the pairwise correlations between all dependent and independent variables. The correlation matrix in Table 3.1 shows that some of the independent variables are highly correlated. More specifically, the responses of the participants concerning the perceived adequacy of the library on books, journals, and databases on POM are highly correlated with the overall perceived assessment of the library. This is expected since the overall evaluation of the library facilities will certainly be affected by the perceptions that respondents have on the individual services provided by the library. Furthermore, perceptions of the adequacy of the computer support services are correlated with the expenditures on computer hardware and software. Interestingly, these last two variables are also correlated with the overall assessment of the library. The high correlation between these three variables suggests that schools focusing on the improvement of their library systems also emphasize on the improvement of their computer facilities. This is not surprising since library and computer facilities improvements are expected to have a high correlation with the overall institutional funding/budget.

From Table 3.1 we also observe the positive and significant correlation $(p<0.001)$ between the two dependent variables and the variable center (this variable indicates the presence or absence of a research center focusing on POM issues). There is also a positive and significant correlation $(p<0.001)$ between the dependent variables and the variable funds-external, which describes the amount of money allocated by external sources to the professors of the POMG for POM research. Note also the positive and significant correlation $(p<0.003)$ of the dependent variable top-10-articles with the variable POM-doctoral, which represents the number of POM doctoral students. One would expect that as the number of doctoral students increases, the number and quality of the articles published by professors of the POMG would also increase. Doctoral students do not only assist with research work, but also provide stimulation and momentum for more research. Furthermore, doctoral graduates during the initial stages of their academic career, tend to publish with their advisors. We argue that the number of doctoral students serves as a proxy for the number of doctoral graduates. Since we examine research productivity over a period of time, the publishing contribution of doctoral graduates is also embedded in the average productivity of the professors in a POMG. Finally, it is interesting to note the positive correlation of the variable library-journals with the two dependent variables $(p<0.005)$. This suggests that a library rich with POM journals may enhance the research productivity in terms of the number of articles and the quality of articles published by professors of a POMG. This result is not surprising, since it is important for a researcher to have access to the work of others while conducting his/her research.

3.2. Regression analysis results. Prior work on factors affecting research productivity focused on such factors as teaching load, consulting activity, size of the faculty, and seniority (Borokhovich et al. [8]; Mitchell and Rebne [23]; Hancock et al. [15]). Factors such as the presence of a research center and external funding have been ignored. We 
8 Factors affecting research productivity of POM groups

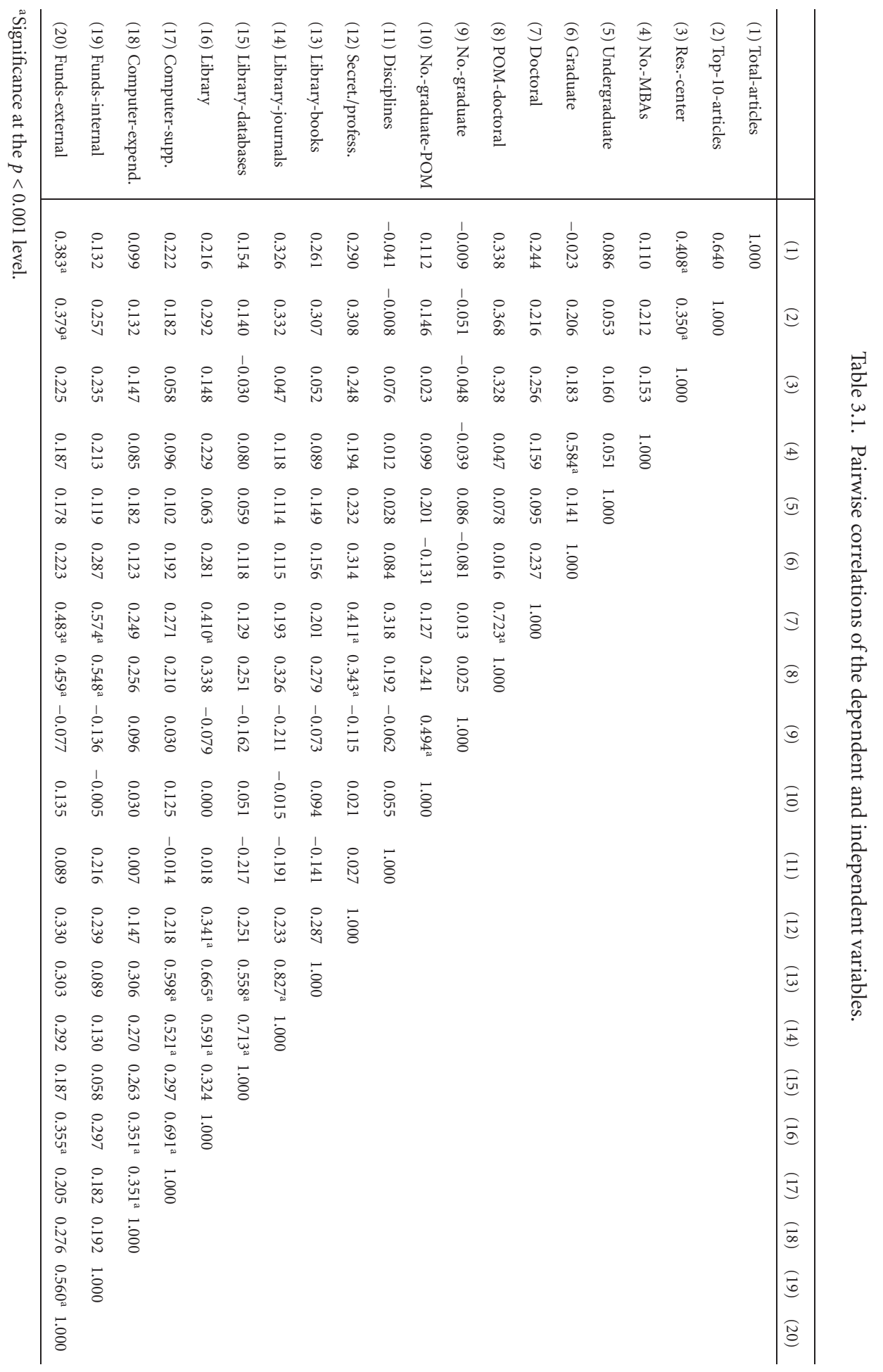


would expect that these factors would promote the research productivity and quality of the articles published by professors of a POMG. This is partly supported by the positive and significant correlations of the two dependent variables with the independent variables center and funds-external. The following two propositions capture the impact of the presence of a research center and external funding on research productivity and quality.

Proposition 3.1. (i) The presence of a research center on POM increases the research productivity (expressed as the average number of articles published per professor) of the POMG.

(ii) The presence of a research center on POM increases the quality (expressed as the average number of articles published per professor in the top-10 POM journals) of the research output of the POMG.

Proposition 3.2. (i) Funds allocated by external sources to professors of the POMG increase the research productivity (expressed as the average number of articles published per professor) of the POMG.

(ii) Funds allocated by external sources to professors of the POMG increase the quality (expressed as the average number of articles published per professor in the top-10 POM journals) of the research output of the POMG.

Using the two dependent variables and the set of independent variables in Table 2.1, we constructed linear regression models. A base model was developed that includes the independent variables center (which indicates the presence of a research center for POM research) and funds-external (which describes the amount allocated to professors of the POMG by external sources for research on POM). The decision to include the above two independent variables in the base model was made because of the significant correlation that these variables exhibit with the dependent variables.

A number of regression models are evaluated. The issue of multicolinearity was accounted for by removing independent variables that were highly correlated. Tables 3.2 and 3.3 present the models with the highest $R^{2}$-adjusted against the base model described above. Table 3.2 clearly shows the positive and significant coefficients of the variables center and funds-external. This implies that the presence of a research center on POM and higher funds allocated by external sources for research on POM topics, result in an increase of the research productivity of the POMG, in terms of the total number of articles published per professor. This result provides support for part (i) of Proposition 3.1 and part (i) of Proposition 3.2.

Table 3.3 also shows that the coefficients of the variables center and funds-external are positive and significant. This indicates that the presence of a research center and funds allocated by external sources to professors of the POMG, lead to a higher number of articles per professor published in the top-10 journals. This result provides support for part (ii) of Proposition 3.1 and part (ii) of Proposition 3.2.

Apparently, the presence of a research center specializing in POM, invigorates research activity of researchers in a POMG by creating synergies among the researchers and focusing their effort on "pure" POM problems. Furthermore, a center at a business school is typically created after the POMG reaches a level of research proficiency. Research momentum is usually enhanced by the focused efforts of the researchers affiliated with the center. In addition, field leaders are often associated with POM research centers. This 
Table 3.2. Results of the regression analysis where the dependent variable is the total number of articles published per professor.

\begin{tabular}{lccc}
\hline \multicolumn{4}{c}{ Dependent variable: total-articles } \\
\hline Model 1 & Model 2 & Model 3 \\
\hline Constant & $2.133^{\mathrm{b}}$ & 0.372 & 0.319 \\
Center & $2.803^{\mathrm{a}}$ & $2.890^{\mathrm{a}}$ & $2.987^{\mathrm{a}}$ \\
Funds-external & $0.551^{\mathrm{b}}$ & $0.395^{\mathrm{b}}$ & $0.413^{\mathrm{c}}$ \\
Library-books & - & $0.319^{\mathrm{b}}$ & $0.310^{\mathrm{b}}$ \\
POM-doctoral & - & - & 0.072 \\
Adjusted $R^{2}$ & 0.263 & 0.328 & 0.332 \\
$F$-value & 14.377 & 13.198 & 9.679 \\
Model significance & 0.000 & 0.000 & 0.000 \\
\hline
\end{tabular}

${ }^{\mathrm{a}} p<0.001,{ }^{\mathrm{b}} p<0.05,{ }^{\mathrm{c}} p<0.10$.

Table 3.3. Results of the regression analysis where the dependent variable is the number of articles per professor that appeared in the top-10 journals (in terms of quality), in the Barman et al. [4] study.

\begin{tabular}{lccc}
\hline & Dependent variable: top-10-articles & \\
\hline & Model 1 & Model 2 & Model 3 \\
\hline Constant & 0.322 & -0.335 & -0.195 \\
Center & $0.978^{\mathrm{b}}$ & $1.003^{\mathrm{b}}$ & $0.701^{\mathrm{c}}$ \\
Funds-external & $0.272^{\mathrm{b}}$ & $0.205^{\mathrm{b}}$ & $0.193^{\mathrm{c}}$ \\
Library-books & - & $0.125^{\mathrm{b}}$ & $0.100^{\mathrm{c}}$ \\
POM-doctoral & - & - & 0.047 \\
Adjusted $R^{2}$ & 0.197 & 0.254 & 0.207 \\
$F$-value & 10.352 & 9.606 & 5.621 \\
Model significance & 0.000 & 0.000 & 0.001 \\
\hline
\end{tabular}

${ }^{\mathrm{a}} p<0.001,{ }^{\mathrm{b}} p<0.05,{ }^{\mathrm{c}} p<0.10$.

attracts other active researchers and the momentum created results in more and betterquality papers.

External funding also results in more and higher-quality papers. In order to receive funds from an external organization, a researcher's work must be perceived as relevant. Typically, real problems are considered as important and receive external funding. When an area of research is perceived by academics or others as relevant and important, it is more likely to be published in the "best" journals of the field. In addition, higher levels of external funding imply that the professor receiving the funding has the resources, either material or collaborative, to generate higher-quality research. External funding also creates pressure on researchers to provide a deliverable that justifies the initial funding. This pressure leads to more and better-quality publications.

Tables 3.2 and 3.3 also show that the independent variable library-books has a positive and significant coefficient. This implies that better library facilities enhance research in 
Table 3.4. Analysis of variance results for POMGs that are (are not) affiliated with a center and POMGs with external funding less (greater) than $\$ 50000$.

\begin{tabular}{|c|c|c|c|c|}
\hline \multicolumn{5}{|c|}{ Mean (std. dev.) } \\
\hline & With center & No center & $F$-statistic & $p$-value \\
\hline Total-articles & $6.2887(2.9771)$ & $3.1514(2.3449)$ & 15.794 & $0.000^{\mathrm{a}}$ \\
\hline Top-10-articles & $1.9664(1.0851)$ & $0.7418(1.1379)$ & 11.159 & $0.001^{\mathrm{a}}$ \\
\hline \multicolumn{5}{|c|}{ Mean (std. dev.) } \\
\hline & $\begin{array}{l}\text { External funding } \\
\text { less than } \$ 50000\end{array}$ & $\begin{array}{l}\text { External funding } \\
\text { greater than } \$ 50000\end{array}$ & $F$-statistic & $p$-value \\
\hline Total-articles & $3.1218(2.2871)$ & $4.3895(3.2237)$ & 3.752 & $0.057^{c}$ \\
\hline Top-10-articles & $0.6276(0.9387)$ & $1.6754(1.5444)$ & 13.247 & $0.000^{\mathrm{a}}$ \\
\hline
\end{tabular}

${ }^{\mathrm{a}} p<0.001,{ }^{\mathrm{c}} p<0.10$.

terms of the quantity and the quality of the articles published. In fact, if we replace the variable library-books with library-journals, we get similar results as those presented in Tables 3.2 and 3.3. The coefficient of the variable POM-doctoral although positive, is not significant in both models used in Tables 3.2 and 3.3. Evidently, we can argue that doctoral students do assist in the creation of more and better papers but they are not the driving force of research productivity or research quality.

3.3. Analysis of variance results. Propositions 3.1 and 3.2 were further explored by performing an analysis of variance test. Two groups of POMGs are used, those that have a research center on POM issues, and those that are not associated with a research center. The analysis of variance shows that when we compare the mean research productivity in terms of the number of articles published per professor by the two groups, the null hypothesis, which states that the two means are the same, is rejected $(p<0.001)$. A closer look at the mean of the two groups, shows that the research productivity in total articles per professor of the POMGs that have a research center is 6.2887 (std. dev. $=2.9771$ ) and for professors of POMGs not associated with a center is 3.1514 (std. dev. $=2.3449$ ). Similarly, the analysis of variance shows that the mean research quality, measured in articles per professor that appeared in the top-10 journals, of POMGs with a center and of POMGs not associated with a center are not the same. The results of the above analysis of variance are shown in Table 3.4. The results clearly show the positive impact of a research center on research productivity and quality.

We next consider the impact of external funding by distinguishing the POMGs represented in this study into two groups. The first group represents POMGs that have received less than $\$ 50000$ of funding from external sources (low level of external funding), during the period of interest, and the second group represents POMGs that have received more than $\$ 50000$ of external funding (high level of external funding) in the same period. In our study, we included five categories in order to capture the levels of external funding. The majority of respondents (71\%) indicated that their POMG received in total less than $\$ 50000$ from external sources. The majority of the remaining 29\% of the respondents indicated that their POMG received an amount between $\$ 50000$ and $\$ 100000$. A very small 
number indicated receiving amounts greater that $\$ 100000$. As a result, we collapsed the five categories into two in order to have sufficient data for the analysis of variance tests to be valid.

An analysis of variance test comparing the mean number of articles published per professor in each group, shows that the means are different $(p<0.1)$. A comparison of the means of the two groups describing the number of articles per professor published in the top-10 journals, presents more evidence that the means are indeed different $(p<0.001)$. The results of this analysis of variance are shown in Table 3.4. This result clearly shows that POMGs with significant amounts of funding from external sources produce more and better-quality articles.

The fact that the presence of a research center on POM and external funding lead to higher productivity (in terms of the average number of articles per professor) and quality (in terms of the average number of articles per professor published in the top10 POM journals), suggests that further investigation should be conducted on a possible interaction between the two variables, that is, center and funds-external. As a result, we formulate the following proposition.

Proposition 3.3. There is a dependency between the presence (absence) of a research center on POM and the level of funding allocated by external sources.

A $\chi^{2}$ test is performed to test the above proposition. We have a contingency table with four cells, indicating the four categories of POMGs that are created by the presence/absence of a research center and whether the POMG received less/more than $\$ 50000$ of funding from external sources. The $\chi^{2}$-statistic is 9.388 indicating that the null hypothesis, which states that the two categories are independent, is rejected $(p<0.005)$. The dependency of a center on the amount of external funding is not surprising since centers usually attract external funding to support their activities.

The fact, however, that the two dimensions are associated with one another, poses another question. What is the impact of the dependency of the presence/absence of a research center on POM issues and the level of external funding, on the research productivity and the quality of the research output? This question leads us to the following proposition.

Proposition 3.4. (i) Research productivity of the four categories of POMGs created by the presence/absence of a research center in POM and the level (low/high) of external funding, is different.

(ii) The quality of the research of the four categories of POMGs created by the presencelabsence of a research center in POM and the level (low/high) of external funding, is different.

The four categories of POMGs presented in the above proposition are (1) POMGs associated with a research center and receiving external funding less than $\$ 50000$, (2) POMGs associated with a research center and receiving external funding greater than \$50000, (3) POMGs not associated with a research center and receiving external funding less than \$50000, and (4) POMGs not associated with a research center and receiving external funding greater than $\$ 50000$. Table 3.5 presents the results of the analysis of 
Table 3.5. Analysis of variance results.

\begin{tabular}{|c|c|c|}
\hline \multicolumn{3}{|c|}{ Variable: total-articles } \\
\hline Group & Mean & Std. dev. \\
\hline (1) With center and less than $\$ 50000$ funding & 7.5000 & 3.5178 \\
\hline (2) With center and greater than $\$ 50000$ funding & 5.5965 & 2.6546 \\
\hline (3) No center and less than $\$ 50000$ funding & 2.7716 & 1.7917 \\
\hline (4) No center and greater than $\$ 50000$ funding & 3.8263 & 3.3912 \\
\hline$F$-statistic & 7.416 & - \\
\hline$p$-value & $0.000^{\mathrm{a}}$ & - \\
\hline \multicolumn{3}{|c|}{ Variable: top-10-articles } \\
\hline Group & Mean & Std. dev. \\
\hline (1) With center and less than $\$ 50000$ funding & 1.312 & 0.944 \\
\hline (2) With center and greater than $\$ 50000$ funding & 2.340 & 1.035 \\
\hline (3) No center and less than $\$ 50000$ funding & 0.574 & 0.926 \\
\hline (4) No center and greater than $\$ 50000$ funding & 1.365 & 1.673 \\
\hline F-statistic & 6.350 & - \\
\hline$p$-value & $0.001^{a}$ & - \\
\hline
\end{tabular}

${ }^{\mathrm{a}} p<0.001$.

variance that tests Proposition 3.4. From Table 3.5 we see that the means of the above four categories of POMGs are different, both in terms of the average number of articles per professor and the average number of articles per professor in the top-10 journals. When comparing the mean research productivity of the four categories of POMGs, the analysis of variance test fails to accept the null hypothesis (which states that the means are the same), since POMGs associated with a center have a higher research productivity. When comparing the quality of the articles, we observe that POMGs that are associated with a center and receive high external funding produce high-quality articles. These findings further suggest that the presence of a research center on POM, external funding, as well as the interaction of the above two, promote the research productivity and the quality of the research of POMGs.

This study implies that POMGs receiving external funding are more productive in terms of research. This finding has significant policy implications for business schools. As such, business schools should consider moving closer to the model adopted by many engineering schools, which place a high value on faculty obtaining outside funding. This is particularly important as the allocation of resources is becoming tighter in many schools, especially in state institutions.

\section{Conclusion}

The research productivity of researchers is perhaps the most important factor determining, among other things, salary raises and promotions. This study identifies factors which drive the research productivity of groups of production and operations management researchers in US business schools. The results of the study support that the presence of a 
research center on production and operations management, increases the productivity of the professors affiliated with the center, in terms of the total number of articles published, as well as the number of articles that have appeared in the elite journals of the field. Furthermore, the results suggest that funding received from external sources by professors of a production and operations management group, increases the number and the quality of the articles published by professors of the group.

The above findings point to two important policy implications for business schools trying to improve their research productivity and quality. First, real-world problems received external funding and have a higher probability of publication. Second, business schools could consider the model adopted by engineering schools, which place a high emphasis on faculty receiving external funding, especially when resources are limited.

The study also shows that better library facilities also promote the research productivity of researchers in terms of the number of articles and their quality. Finally, the number of doctoral students associated with a group of production and operations management academics, promotes the research productivity and the quality of their research output. However, doctoral students cannot be regarded as the driving force behind research productivity and quality.

This study is certainly not without limitations. One limitation is the fact that one important variable had to be dropped because of poor response. In particular, this variable was related to the teaching load of the professors. One would expect that the average teaching load will have a negative impact on the research productivity of a professor. As such, the results of our exploratory study must be used in conjunction with the results of other studies that have considered the impact of the teaching load on productivity. Since the level of analysis in our study is a group of production and operations management academics, the study did not consider information describing the professors as individuals. Such information includes professorial rank, salary, consulting activity, and rank of institution. These factors could be used in future studies.

Finally, future work can also incorporate other objective measures of research quality such as citations count, since the classification of journals based on the perceptions of the researchers may hide biases. This need was also highlighted in a comment accompanying the study by Hancock et al. [15], which stressed the importance of adopting different measures of research productivity such as, for example, the number of times the researcher's work is cited by others.

\section{References}

[1] A. Ansari, D. Lockwood, and B. Modarress, Characteristics of periodicals for potential authors and readers in production and operations management, International Journal of Operations and Production Management 12 (1992), no. 6, 56-65.

[2] C. Baden-Fuller, F. Ravazzalo, and T. Schweizer, Making and measuring reputations: the research ranking of European business schools, Long Range Planning 33 (2000), no. 5, 621-650.

[3] S. Barman, M. D. Hanna, and R. L. LaForge, Perceived relevance and quality of POM journals: a decade later, Journal of Operations Management 19 (2001), no. 3, 367-385.

[4] S. Barman, R. Tersine, and M. R. Buckley, An empirical assessment of the perceived relevance and quality of POM related journals by academicians, Journal of Operations Management 10 (1991), no. 2, 194-210. 
[5] J. Benjamin and V. Brenner, Perceptions of journal quality, The Accounting Review (1974), 360362.

[6] B. B. Billings and G. J. Viksnins, The relative quality of economics journals: an alternative ranking system, Western Economic Journal 10 (1972), 467-469.

[7] S. Bonzi, Trends in research productivity among senior professors, Information Processing and Management 28 (1992), no. 1, 111-120.

[8] A. Borokhovich, R. J. Bricker, K. R. Brunarski, and B. J. Simkins, Finance research productivity and influence, Journal of Finance 50 (1995), 1691-1717.

[9] R. K. Coe and I. Weinstock, Evaluating the finance journals: the department chairperson's perspective, The Journal of Financial Research 6 (1983), 345-349.

[10] _ Evaluating the management journals: a second look, Academy of Management Journal 27 (1984), 660-666.

[11] L. H. Ederington, Aspects of production of signicant financial research, Journal of Finance 34 (1979), 777-786.

[12] C. Goh, C. Holsapple, L. Johnson, and J. Tanner, Evaluating and classifying POM journals, Journal of Operations Management 15 (1997), no. 2, 123-138.

[13] P. E. Graves, J. R. Marchant, and R. Thomson, Economics departmental rankings: research incentives, constraints, and efficiency, The American Economic Review 72 (1982), 1131-1141.

[14] V. Grover, A. H. Segars, and S. Simon, An assessment of institutional research productivity in MIS, Database 23 (1992), no. 4, 5-9.

[15] T. Hancock, J. Lane, R. Ray, and D. Glennon, The ombudsman: factors influencing academic research productivity: a survey of management scientists, Interfaces 22 (1992), 26-38.

[16] R. G. Hawkins, L. S. Ritter, and I. Walter, What economists think of their journals, Journal of Political Economy 81 (1973), 1017-1032.

[17] F. A. Jacobs, A. L. Hartgraves, and L. H. Beard, Publication productivity of doctoral alumni, The Accounting Review 61 (1986), 179-186.

[18] L. R. Jaunch and W. Glueck, Evaluation of university professors' performance, Management Science 22 (1975), 66-75.

[19] R. C. Klemkosky and D. L. Tuttle, The institutional source and concentration of financial research, Journal of Finance 32 (1977), 901-907.

[20] D. N. Laband, An evaluation of 50 ranked economics departments-by quantity and quality of faculty publications and graduate student placement and research success, Southern Economic Journal 52 (1985), 216-240.

[21] S. J. Liebowitz and J. P. Palmer, Assessing the relative impacts of economics journals, Journal of Economic Literature 1 (1984), 77-88.

[22] M. K. Malhotra and H. V. Kher, Institutional research productivity in production and operations management, Journal of Operations Management 14 (1996), no. 1, 55-77.

[23] J. E. Mitchell and D. S. Rebne, Nonlinear effects of teaching and consulting on academic research, Socio-Economic Planning Sciences 29 (1995), no. 1, 47-57.

[24] W. J. Moore, The relative quality of economics journals: a suggested rating system, Western Economic Journal 10 (1972), 156-169.

[25] A. W. Niemi, Institutional contributions to the leading finance journals, 1975 through 1986: a note, Journal of Finance 42 (1987), 1389-1397.

[26] _ Publication performance of marketing departments: 1975-1985, Journal of Marketing Education 10 (1988), 8-12.

[27] _ Research productivity of American business schools, 1975-85, Review of Business and Economic Research 23 (1998), 1-17.

[28] B. Saladin, Operations management research: Where should we publish?, Operations Management Review 3 (1985), 3-9. 


\section{Factors affecting research productivity of POM groups}

[29] A. D. Sharplin and R. H. Marby, The relative importance of journals used in management research: an alternative ranking, Human Relations 38 (1985), 139-149.

[30] J. W. Skeels and R. A. Taylor, The relative quality of economics journals: an alternative rating system, Western Economic Journal 10 (1972), 470-473.

[31] A. C. Soteriou, G. C. Hadjinicola, and K. Patsia, Assessing production and operations management related journals: the European perspective, Journal of Operations Management 17 (1999), no. 2, 225-238.

[32] M. J. Stahl, T. L. Leap, and Z. Z. Wei, Publication in leading management journals as a measure of institutional research productivity, Academy of Management Journal 31 (1988), 707-720.

[33] D. Vogel and J. Wetherbe, MIS research: a prole of leading journals and universities, Database 16 (1984), 3-14.

[34] R. Vokurka, The relative importance of journals used in operations management research: a citation analysis, Journal of Operations Management 14 (1996), no. 4, 345-355.

[35] R. P. Weber and W. C. Stevenson, Evaluations of accounting journals and department quality, Accounting Review 56 (1981), 596-612.

[36] M. J. White and G. White, Citation analysis of psychology journals, American Psychologist 32 (1977), 301-305.

[37] S. Young, B. Baird, and M. Pullman, Research productivity in U.S. business schools, Journal of Operations Management 14 (1996), no. 1, 41-53.

George C. Hadjinicola: Department of Public and Business Administration,

School of Economics and Management, University of Cyprus, Kallipoleos 75 Street,

P.O. Box 20537, 1678 Nicosia, Cyprus

E-mail address: bageorge@ucy.ac.cy

Andreas C. Soteriou: Department of Public and Business Administration,

School of Economics and Management, University of Cyprus, Kallipoleos 75 Street,

P.O. Box 20537, 1678 Nicosia, Cyprus

E-mail address: basotir@ucy.ac.cy 


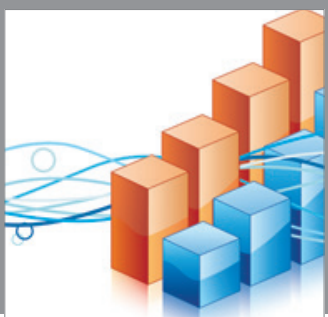

Advances in

Operations Research

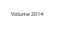

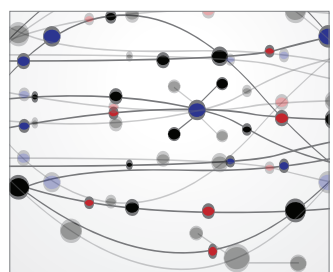

\section{The Scientific} World Journal
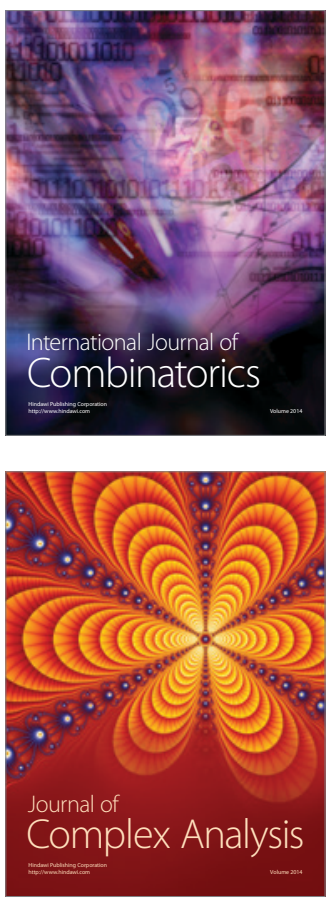

International Journal of

Mathematics and

Mathematical

Sciences
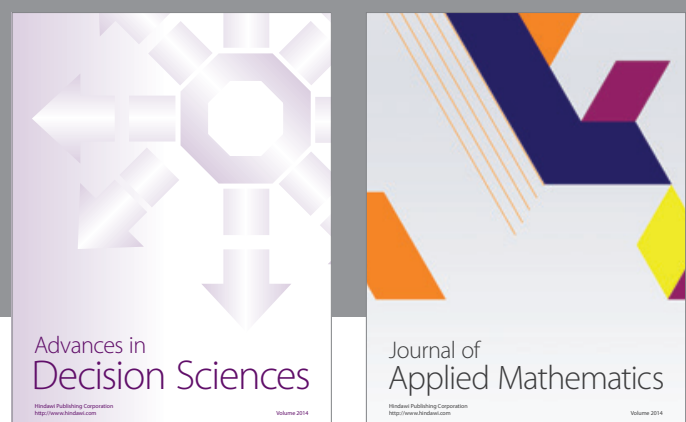

Journal of

Applied Mathematics
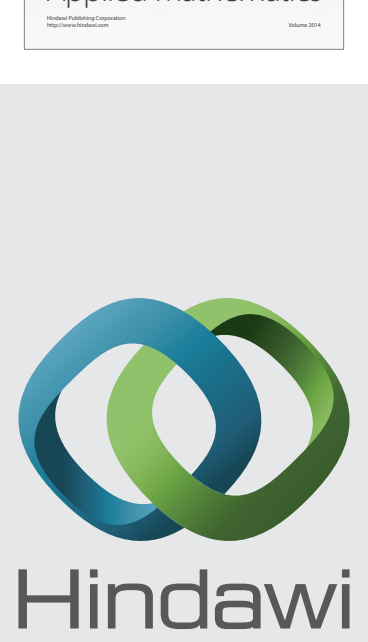

Submit your manuscripts at http://www.hindawi.com
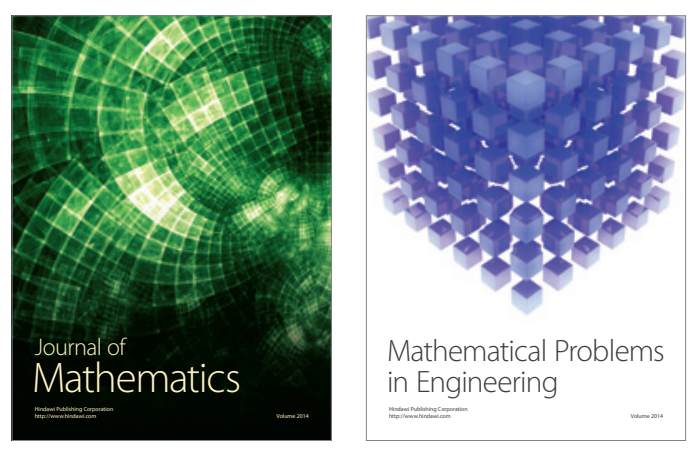

Mathematical Problems in Engineering
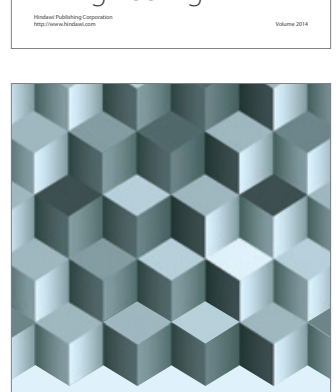

Journal of

Function Spaces
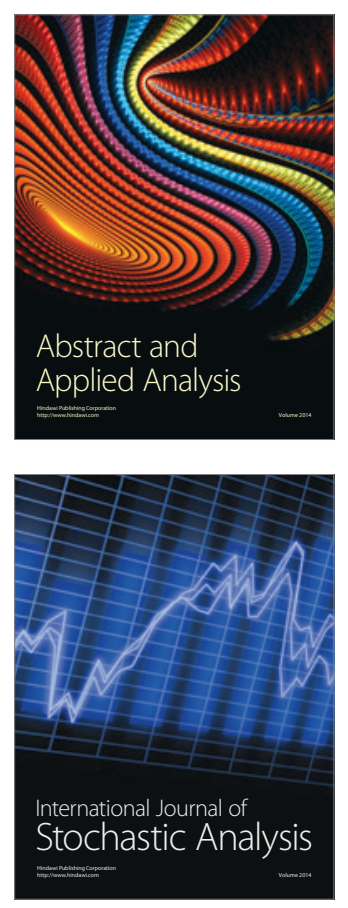

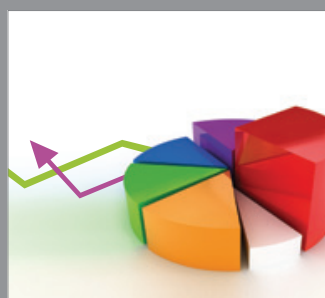

ournal of

Probability and Statistics

Promensencen
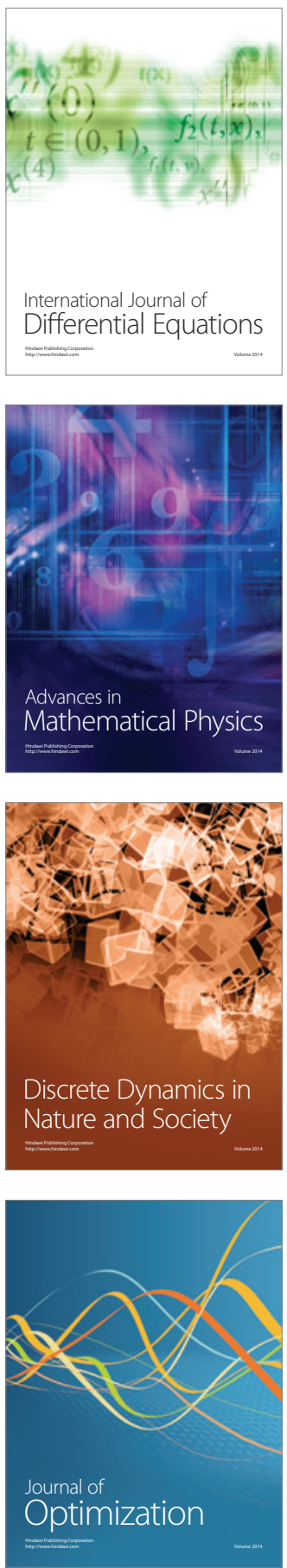